\title{
\#iteachmsu: Centering an Educator Learning Community (ELC)
}

\author{
Erik Skogsberg, Makena Neal, Melissa McDaniels, \\ Maddie Shellgren, and Patricia Stewart
}

\begin{abstract}
Many scholars recommend preparing faculty for educator roles. Faculty learning communities, the scholarship of teaching and learning (SoTL), and teaching centers represent common preparatory approaches. But faculty and teaching assistants report time, disciplinary disconnects, and lack of incentives as ongoing barriers. Inspired by K-12's professional learning networks and "hashtag activism," the authors' university launched \#iteachmsu. \#iteachmsu combines practices of social networking with a digital and in-person teaching "commons." Through \#iteachmsu, the authors hope to further shift campus cultures in the age of COVID-19, centering teaching and learning as a valuable and ongoing focus for an educator learning community (ELC).
\end{abstract}

Keywords: centers for teaching and learning, faculty learning communities, digital learning, institutional change, social media

\#iteachmsu. A hashtag. A statement. A public declaration of pride in one's teaching practice and educator identity. We deliberately use the term educator development to not only highlight the development of individual practice but also refer to the wide variety of educator identities that support the teaching and learning mission of the university. 
Educators could include but are not limited to faculty, graduate teaching assistants, undergraduate learning assistants, instructional designers, academic advisors, and administrators. And educator practices can span the curricular and co-curricular and the classrooms, hallways, residence halls, and sidewalks across campus communities. We, a group of educator developers at a large research institution, are rarely surprised when we work with educators reticent to publicly make the declaration, \#iteachmsu, on our campus. Like those at many campuses, our educator colleagues at Michigan State University (MSU) often bring identities and priorities that have not been perceived as historically important by the institution. Research, promotion, and tenure policies have disproportionately valued research over teaching in institutions such as ours. We have found multiple educators on our campus to be regularly dissuaded by well-meaning mentors who warn against investing too much time in their teaching development. And now, in the age of COVID-19, we are witnessing rapid and fundamental shifts in modes of educational delivery, pedagogy, and even in the value proposition of a higher education. As we traverse the uncertainty brought by this public health crisis and a shift to remote and online education, this more encompassing definition of "educator" is even more vital.

Throughout 2020 and into 2021, traditional educators were required to make massive and immediate changes in their practice. That said, the behind-the-scenes heroes supporting those changes are the other educators on campus: information technology services, learning experience designers, work-life offices, infrastructure and facilities staff. We seek to leverage "\#iteachmsu" to anchor our face-to-face and digital educator teaching "commons" (Huber \& Hutchings, 2005) and campus-wide educator learning community (ELC) (i.e., an expansion of the traditional faculty learning community to include the broader educator definition) for the higher education of now and beyond. In utilizing \#iteachmsu as an ELC, we are able to center teaching and learning across our campus and facilitate a wider sharing of educator ideas and resources, enhance community building, and support growing in 
teaching practice. Despite the challenges, and to leverage important opportunities for reframing, we are committing to building new narratives and practices for high-quality teaching and learning across faceto-face and digital spaces.

Discussing the \#iteachmsu story must begin with noting the rapidly changing landscape for educator development at institutions across the United States. Many centers for teaching and learning (CTLs) have matured and been institutionalized. With this maturation, CTLs are being called on to do more than they have in the past: breaking down institutional silos, navigating hybrid professional identities, and leading change, all the while building their evidence of impact in ways that will be valued by multiple internal and external stakeholders (Beach et al., 2016; Kelley et al., 2017). Wright et al. (2018) noted their belief that we have arrived at a "de-centered" moment in which a CTL can serve as essential "hosts or facilitators of institutional initiatives, playing a 'hub' role through course or learning space design with cross-campus teams, and disseminating [emphasis added] knowledge and exemplars about teaching and learning across campus" (p. 42). A recent matrix from the American Council on Education and POD Network (2018) noted that an exemplary teaching center is one that "collaborates with other centers, or disseminates to a wider audience" (p. 7). However, Froyd et al. (2017) cautioned against a "dissemination paradigm," centered on raising awareness of scholarly teaching practices, as they potentially miss key educator realities that keep educator developments from spreading. We believe a CTL has, can, and will continue to play a key role in educator development across a campus. However, to address the limits of a dissemination paradigm, we believe that our work as educator developers should focus on centering teaching and learning across multiple hubs: programs, departments, colleges, and other administrative units.

Our university does not have a CTL, and across our multiple teaching support units, we've watched attendance rates continue to decline at traditional one- or two-hour in-person teaching workshops. Our robust portfolio of learning communities for faculty and graduate 
students have only reached a small percentage of educators. And we also continue to hear both direct and indirect stories of educators feeling isolated in their teaching work, struggling to connect with others who share their teaching interests and passions. Overall, we've found that prevailing institutional approaches to educator development have rarely provided for the kind of sustainable educator learning and reflective practice needed to improve student success at scale. We, a group of educator developers working in a variety of central administrative offices, believe a different approach is needed.

So we have recently chosen to focus on supporting decentralized teaching innovation across our many colleges and departments through \#iteachmsu and an ELC approach to our work. In doing so, we've experienced the affordances (e.g., autonomy and disciplinebased local innovations) and constraints (e.g., scattered resources, lack of campus-wide commitments to teaching and learning) of such decentralization. Increasingly, it has us wondering, how might we further center educator development as a priority at our large research institution without relying on traditional centralized structures typically used in educator development work?

In this article, we have three aims. First, we want to contribute to the scholarly literature on faculty and graduate teaching assistant development by framing a discussion of the potential role that a higher education-focused ELC and hashtag movement might play as institutions negotiate future directions for higher education. Second, we want to share one innovative model (\#iteachmsu at our university) being used to design a higher education ELC that promotes pedagogical skill development among a decentralized community of educators and promotes cultures that value and enable high-quality and inclusive teaching and learning. And finally, we want to share our reflections about the benefits and challenges of implementing this design in light of the research literature and the impacts of today's global pandemic, concluding with implications and recommendations for practice broadly and in the time of necessary online teaching brought on by the COVID-19 pandemic as well as opportunities for future research. 


\section{The Current Educator Development Context}

Typically, when an individual thinks of an educator in postsecondary higher education, they think of a faculty member. The roles of these educators at institutions of higher education have been thought of as dynamic and multifaceted. Speaking to this, Boyer (1990) outlined multiple forms of scholarly activity that faculty undertake; these include the scholarship of "discovery," "integration," "application," and "teaching." To engage in high-quality teaching, a faculty member must bring together multiple and dynamic practices and knowledges across disciplines and varying contexts (Hollins, 2011; Shulman, 1986, 1987). Learning to teach goes beyond "acquiring skills and best practices. It involves adopting the identity of a teacher, being accepted as a teacher, and taking on the common values, languages, and tools of teaching" (Lampert, 2010, p. 29). Faculty content knowledge, family upbringing, social and political contexts, and particular pedagogical teaching knowledge influence the way faculty develop and make meaning of their professional identities as teachers. These factors, along with institutional and organizational culture, impact the way faculty design and teach their courses as well as whether they are valued in doing so (Oleson \& Hora, 2014). And sometimes organizational cultures can be at odds with developing these educators' practices.

At many institutions, particularly those that are research intensive, faculty are still often hired for and evaluated on their cutting-edge research, despite calls for a greater balance between research and teaching in faculty evaluation and institutional promotion and tenure processes (Brew, 2006; Li-Ping Tang \& Chamberlain, 1997; Locke, 2012). This reality, combined with the increasing pressure on faculty to be active community members (at the university and beyond), presents challenges to faculty who want to invest in their own development as teachers but are faced with these very real-time limitations. These cultural barriers affect graduate teaching assistants as well.

Graduate teaching assistant educators find themselves facing similar challenges as faculty interested in developing teaching practice (but 
absent the power the institution provides them via their role). Austin and McDaniels (2006) found frictions magnified for graduate students for whom teaching is a key part of their socialization to the academy. Although support for graduate student teaching development has increased over the past several decades, many graduate students do not receive systematic preparation for roles as teaching assistants or future faculty. Beliefs and assumptions about teaching held by faculty begin to develop during graduate school, which sometimes means new faculty simply imitate behaviors they witnessed their own faculty educators employ as a model-for better or worse (Oleson \& Hora, 2014). And even if these new educators are not consciously trying to build a teaching philosophy, they can quickly form patterns or lasting styles and persistent attitudes toward teaching based on their beginning practices (Boyle \& Boice, 1998). So centering both faculty and graduate teaching assistant educators in optimal practice is essential. And although this centering might happen through formal, institutionally sanctioned, and individually constructed activities, predominantly these educators will interact with other educators who have similar motivations in "communities of practice" (CoPs).

CoPs are groups of individuals who come together to reflect on collective learning through shared norms and practices (Wenger, 2000). These communities allow for "developing an identity as a member of a sustained community and becoming knowledgeably skillful . . . , with the former motivating, shaping, and giving meaning to the latter" (Lave, 1991, p. 65). CoPs create space for context-specific growth while offering the flexibility that comes with competence being defined by the group. In institutions of higher education, a popular CoP approach across institutions to support educator development has been faculty learning communities (FLCs).

\section{Face-to-Face FLCs for Developing Faculty and Courses}

FLCs have provided an essential foundation for educator development across higher education. Originally conceived by Milton D. Cox with 
the development of the Miami Teaching Scholars Program in 1995 and officially coined in 1999, FLCs are defined as a "cross-disciplinary group of ten or so teachers who engage in an extended (typically yearlong) planned program to enhance teaching and learning and which incorporates frequent activities to facilitate learning, development, and community building" (Cox, 1999, p. 40). In FLCs, coordinators establish specific structures and processes to help faculty members create opportunities for collaborative learning and growth in a socially supportive structure. FLCs can be focused on general institutional objectives or around a specific topic (Banasik \& Dean, 2016). Regardless of FLC goals, these faculty communities are usually bounded by a specific timeline and involve a specific cohort of participants (Eddy \& Garza Mitchell, 2012).

Banasik and Dean (2016) note community building, institutional knowledge, and awareness and application of diverse teaching styles as benefits of FLCs. Learning is also an inherent characteristic of FLCs, with possibilities of bringing together multiple perspectives in regard to things such as pedagogy, institutional role, or discipline. A structure of physical, regular meetings historically binds FLCs to face-to-face spaces (Banasik \& Dean, 2016; Eddy \& Garza Mitchell, 2012). And as Cox (2013) found, FLCs do in fact impact early-career faculty attitudes toward teaching and learning. But while the structure and in-person nature of FLCs have historically contributed to some faculty educator development successes, these facets also contribute directly to the barriers that can inhibit participation in a campus-wide educator community of practice during normal times, let alone during this time of pandemic and necessary online interaction. Scheduling difficulties and time along with disciplinary culture and varied reward or recognition structures are all commonly reported barriers to participation in an FLC pre-pandemic (Hubbal \& Albon, 2007; Shulman et al., 2004). Little is also known about how educators outside of faculty are responding, despite the fact that FLC CoPs employed within and across disciplines and roles can help shape universities into learning organizations (Cox, 2013). Clearly, additional steps can be taken to further realize 
improvement in educator development building out of the FLC model. And some of these steps are currently happening by bringing FLCs into digital spaces.

\section{Digital FLC Approaches}

New technologies have recently opened new possibilities and challenges for promoting teaching development and FLC-like programs. Over the past many years, higher education administrators and offices of professional development have turned to technology-enabled faculty community networks (Hanraets et al., 2011). And as Wright and her colleagues from POD (2018) pointed out, there are an increasing number of fee-based, online educator development products emerging in the marketplace. These tools offer great potential for sharing evidence-based practices in teaching. In tandem, applications of technology for student learning in higher education have grown exponentially, extending beyond functions for student learners to tools for learning among faculty and other educators on a campus.

Utilizing digital tools to facilitate or enhance communication and idea sharing in higher education is not new (Davis \& Holt, 1998). The literature on using new media suggests that social software such as blogs can be used to encourage personal reflection and critical thinking as well as the development of writing and communication skills (Joshi \& Chugh, 2009). Technology, if used thoughtfully, may help institutions address acknowledged barriers to educator participation in professional development (e.g., time constraints, disciplinary culture) and make ELCs more accessible across space and time.

For example, social networking sites (SNSs) and blogs allow faculty to communicate in real time regardless of schedules, collaborate synchronously and asynchronously, and track individual learning over time (Eddy \& Garza Mitchell, 2012). These spaces allow educators to "reach beyond the uni-directional information provision typical of many scholarly communication efforts to connect with readers and compel them to look critically at sources of information; to search 
out more information; and, ultimately, to influence practices" (Powell et al., 2012, p. 280). Furthermore, these tools are social, making collaboration across departments easier, allowing them to be "discovered, followed, and perhaps joined by students and faculty around the world" (Alexander, 2006, p. 40). Additionally, literature on online faculty development shows that online faculty development portals are effective in developing, facilitating, and sustaining faculty involvement (Sherer et al., 2003). Through these digital approaches, collaboration and faculty educator learning then becomes more possible across large and increasingly decentralized units, colleges, departments, and higher education institutions.

There is tremendous potential in leveraging digital spaces such as SNSs and blogs for educator learning. And while much of the scholarship around social software applications in higher education focuses on teaching or college students' learning (Manca \& Ranieri, 2013), these findings can also apply to educators as learners in community networks. Recent experiences of "shelter in place" orders and remote work have expedited the need for this technology-enhanced transition. Not only are educators in need of resources and opportunities to grow in their online teaching practice, but orders to remain socially distant have also inherently increased isolation. Building a sense of community via an online space is more important than ever. When it comes to professional development and self-directed learning, people mostly rely on acquaintances (e.g., weak ties) with other individuals whom they deem competent and trustworthy (Hanraets et al., 2011). Like FLCs, SNSs create opportunities for collaborative learning and community building through their multi-directional, user-generated design.

Community members can log on to their SNSs, pose questions, share resources, and engage in dialogue, learning with and from one another (Banasik \& Dean, 2016; Cox, 2004; McLoughlin \& Lee, 2008). SNSs also create a platform or space for users to be reflective on both an individual and community level (Eddy \& Garza Mitchell, 2012). Where FLCs have had barriers such as scheduling, time, and culture to 
educator participation (Hubbal \& Albon, 2007; Shulman et al., 2004), SNSs do not require face-to-face time or geographically specific locations or specifically organized cohorts. And there is already evidence in $\mathrm{K}-12$ that this shift toward a social networking approach for educator development can sustain an ongoing and dynamic educator-driven commitment for teaching growth.

\section{Lessons From Professional Learning Networks and Hashtagged Networking}

Across $\mathrm{K}-12$, technological advances have been key to the development and influence of educators. Primary in this advancement have been professional learning networks (PLNs). Grown through SNS spaces, PLNs are a "system of interpersonal connections and resources that support informal learning" (Trust, 2012, p. 133). PLNs have been spurred by K-12 educators' want for teacher networking and development and used to drive key cultural changes (Baker-Doyle, 2017; Trust, 2012; Warlick, 2009). Learning from K-12 PLN networks and best leveraging digital and social technologies stand to potentially advance growth in evidence-based teaching practices for higher education.

In K-12, PLNs have been a key part of contemporary teaching professional development. These networks have become a regular space for educators to engage in both synchronous and asynchronous educator learning, leveraging the collective wisdom of colleagues for their growth in teaching practice (Bauer, 2010; Trust, 2012; Warlick, 2009). With a user-generated design such as a PLN, educators can self-identify topics related to teaching in which they have some experience or expertise and then share a blog post. Microblogging (Twitter) and blogging are additional spaces for educator PLNs and have also been found to enable real-time conversation between learners and instructors-augmenting learning conversations and leading to more dynamic experiences (George \& Dellasega, 2011). In the case of PLNs, users fluctuate in their roles as both learners and teachers. 
Furthermore, PLNs have been an essential part of building teacher agency and justice-oriented "transformative teaching," inspired byand part of-a larger discourse of social media and hashtag activism for social change (Baker-Doyle, 2017). Hashtag activism is a form of "discursive protest on social media united through a hashtagged word, phrase, or sentence" (Yang, 2016, p. 13). Movements such as \#BlackLivesMatter and \#MeToo, as well as \#syllabi such as \#fergusonsyllabus, have powerfully shown that this form of activism across classrooms and communities can dramatically influence social change. And while the movement we're facilitating across MSU is vastly different than these necessary movements for justice in terms of its genesis, identities, and scope, we are deeply inspired by what we've witnessed in terms of the power of individuals leveraging social media to make needed change.

All that said, the literature also suggests that there are challenges that cannot be mitigated by a shift to social software and PLNs alone. Recognition and rewards structures at institutions of higher education are built around traditional exemplars of professional growth and development (Powell et al., 2012). The design and launch of a PLN can be intimidating, as the possibilities are constantly growing and shifting with the emergence of new social software and social software affordances (Sherer et al., 2003). While participation and much content are left up to the users of a PLN, there is also the need for a designated facilitator (Hanraets et al., 2011), but who serves in that role and where they are housed in relation to their other institutional roles can be another challenge.

Additionally, a largely asynchronous and digital approach to educator development still needs to leverage the existing resources available, involve key campus stakeholders in decisions around use, pay close attention to the specific institutional cultures and educators, and gather and provide essential evidence of initial and longer-term impacts (Wright, 2016). Lastly, there are inherent challenges with a PLN being completely voluntary and technologically based. Some individuals may want to participate but not have the confidence with 
their social software skills to join, and others who do have that confidence and volunteer to join may not be representative of diverse perspectives, resulting in an institutional echo chamber of sorts (Davis \& Holt, 1998). Yet the unprecedented shift to remote work and education increases the necessity or pressure to participate in PLNs. Even so, in pre-pandemic times, we believe the affordances outweigh the constraints.

We believe building out the promising foundation of FLCs and PLNs toward a campus-wide ELC to be a better way forward. Where FLCs work to develop a community with a physical presence on campus, expansion to PLNs through an ELC affords users access to resources and connections outside of their physical space and personal time availability. Because PLNs have aspects that are similar to FLCs, they could result in similar outcomes of reflective, collaborative learning by further bringing together educators from multiple perspectives, fields, and disciplines. This means building upon the strengths of current FLC models and moving beyond their limits to a digital and face-to-face ELC model.

We introduce, in our next section, an innovative model for centering an ELC that we have begun on our campus: \#iteachmsu. Through \#iteachmsu we have begun to combine the best affordances of both face-to-face and digital approaches to educator development. We will discuss some of our initial work and imagine a campus-wide version across educator roles and identities. This ELC has been facilitated by further developing a digital and in-person teaching "commons" (Huber \& Hutchings, 2005), linked by a hashtag across both digital and face-to-face spaces. Current efforts in the time of COVID-19 have been focused on the digital commons as a platform for sharing resources, building community, and aiding in educator development. This ELC aims to develop teaching competence in evidence-based practice for a broad range of educators (e.g., faculty, graduate teaching assistants, undergraduate learning assistants, learning experience designers, and advisors) toward sustaining cultures of teaching and learning across higher education. 


\section{The Model: \#iteachmsu as an ELC}

Much of our work toward \#iteachmsu began through a graduate student-led effort called Inside Teaching MSU (ITMSU) in our Graduate School. ITMSU was an effort dedicated to promoting teaching excellence through conversation and sharing practices for graduate teaching assistants (GTAs). We launched ITMSU to catalyze the expertise of many GTAs and instructors that could be shared with colleagues across disciplines. The launch of ITMSU coincided with our university's recognition that traditional models of running workshops for GTAs were falling short of our goals to reach as many people as possible and to build capacity for high-quality graduate student teaching at our university.

ITMSU used three primary social software platforms to build a digital community around teaching and learning: microblogs (Twitter), Facebook, and a university-hosted blog. Through its user-generated, university-hosted blog, ITMSU also aimed to challenge the conventional ideas of who is an educator and where learning takes place. Any member of the institutional community was encouraged to submit an idea related to teaching and learning for the blog, and educators across levels and roles took up this opportunity. The Graduate School at our university has funded ITMSU graduate fellowships since 2015, and the selection and development of the ITMSU Twitter, Facebook, and blog were all a result of graduate fellow dialogues and efforts. ITMSU also hosted multiple \#iteachmsu Twitter EdChats, each of which was guided by a theme and a set of core questions. Reflecting our desire to attract participants who were not active (or even present) on the Twitter platform, we hosted face-to-face gatherings during these EdChats to promote the broadest participation possible.

Over the years, SNS analytics showed increasing and steady digital engagement from individual educators and multiple units across campus in ITMSU's offerings, even while the number of face-to-face workshop participants continued to decrease. What most surprised us was the growing number of participants representing multiple 
groups of educators on campus, including faculty, academic advisors, academic specialists, and both undergraduate and graduate students. A growing community of educators spanning both face-to-face and digital spaces and educator identities was linked through shared interest in sharing resources, connecting with other educators, and growing in their teaching practice. ITMSU-and the introduction of \#iteachmsu - created a promising start for an ELC to build on the initial foundations of FLCs and PLNs while using social software, SNSs, and a common hashtag to overcome traditional community barriers to participation.

As we mentioned above, \#iteachmsu has increasingly been taken up by educators across identities inside and beyond our university. We now believe we can go further and, with the help of an external developer, have initiated a shift toward a campus-wide \#iteachmsu ELC. In the fall of 2020, on the heels of a rapid shift to remote and online teaching, we deliberately scaled \#iteachmsu, our ELC, out across campus and educator roles through the launch of an \#iteachmsu Commons. It has become the place for educator conversations and a curation space for teaching and learning resources and collections and has even helped to launch key university-wide educator initiatives, such as our university's mid-semester course feedback process. The commons has been essential for promoting teaching and learning excellence during a fall semester like our university has never seen before.

Where historically ITMSU was a combination of efforts that included SNSs and a graduate educator blog, the \#iteachmsu Commons shifts this ELC effort in a more intentional way, providing a core foundational website to support our institution's educator development conversations and efforts. The site, iteach.msu.edu, is an educator-driven space, which means the content is solely contributed and shaped by current educators on our campus. Any member of our community who helps contribute to the teaching and learning mission of the university can log on to the site with their affiliated credentials and share their ideas, reflections, resources, questions, and celebrations through posts (shorter format) or articles (longer format). 
Additionally, the \#iteachmsu Commons site has core functions that support expanding educator networks and self-directed growth. A campus-wide teaching and learning events calendar helps educators stay aware of what is happening on campus_reducing siloing and increasing opportunities to collaborate and participate. Educator profiles offer users the opportunity to share their personal and scholarly interests, which can be read by others to inform connections. After users connect with one another, they can even start private messaging. To support ongoing growth, playlists are curated collections of articles, compiled by users or by units on campus for public consumption. Assessments can be stand-alone or integrated into a playlist to help users evaluate their learning, and badges are informal credentials that users can earn with the completion of some playlists. How this site should function as a core part of the ELC on our campus was determined with the help of an advisory group with representation from educators across diverse roles. Their feedback, combined with that from multiple real-user prototype tests, has been provided on a regular, ongoing basis to our development partners to bring this platform to fruition for fall 2021.

There is no administrative oversight to approve or deny shared content. Instead, users are asked to assign their content one of five core categories (Assessing Learning, Incorporating Technologies, Navigating Context, Pedagogical Design, or Disciplinary Content), which are aligned with other educator development efforts on our campus. If a user cannot determine an appropriate category for their contribution, it signals that the \#iteachmsu Commons isn't the best place for sharing. This provides a centralized structure for user-driven, educatorcentered, and educator-driven development. In doing so, we hope to further build an inclusive educator community across campus.

Through diverse representation of educators on our project team and the project's advisory board, we have built the \#iteachmsu Commons website to appeal to multiple educator user roles. For example, GTAs can find multiple articles and playlists related to classroom policies, authored by the Graduate School and partners such as the 
Ombudsperson's Office and Prevention Outreach and Education office. A new faculty member might post a question about effective syllabus review for other educators to comment on with ideas and experiences. When working with a learner who is having difficulty adjusting to university life and expectations, an academic advisor might search the "Navigating Context" category for tips and experiences that they can utilize to inform their future engagements with that learner. A postdoc who has participated in one of the \#iteachmsu Commons asynchronous question and answer events found a new colleague who has expertise in incorporating comic books into pedagogical design. They connect on the site and have an ongoing conversation via messages. With this launch comes considerable excitement around the hopes we have for this commons and ELC moving forward. This launch also raises multiple questions and concerns about the purpose of our work, the best ways to center teaching and learning across campus, and how we might best continue to build a sustainable community inclusive of multiple educator identities.

As a team, we represent various educator networks, roles, and experiences. Our author group has become deeply connected across our diverse work and identities as educators through \#iteachmsu. In fact, we believe that some of the initial evidence of the impact of \#iteachmsu, in addition to what we found working with ITMSU and our Graduate School, to be our collaboration. Representing multiple units (and roles) supporting educators across campus-MSU's Hub for Innovation in Learning and Technology (Erik), the MSU Graduate School and Postdoctoral Office (Makena, Melissa, and Maddie), and MSU's Academic Advancement Network (Patti)—our diverse group hopes for much from this key evolution in approach. We believe the simple fact that we, diverse educators, located across different aspects of the institution, centering teaching and learning change work, are proof of the initial and longer-term potential of centering teaching across the ELC of \#iteachmsu.

An ELC, such as \#iteachmsu, is one possible solution to our contemporary educator development challenges. Using social software 
and social networking sites to leverage digital spaces for collaboration, information exchange, and resource sharing allows educators to engage when they are personally motivated, beyond traditional time and physical space barriers. Furthermore, approaching programming through a lens inclusive of multiple educator identities and with a focus on multiple sources of expertise and sharing stands to reinvigorate traditional approaches (e.g., workshops, learning communities) that continue to be staples in our education development. Key components of an ELC at an institution of higher education would include the following:

- Use of multiple digital platforms. Educators across our campus have a variety of experiences and comfort levels with more closed and/or open digital platforms (our internal \#iteachmsu Commons vs. more open social media). To make sure we're engaging with the broadest audience, cultivating an inclusive educator community, and also building educators' digital presence skills, we recommend facilitating your ELC conversation across both internally facing and externally facing platforms and deliberately modeling key digital practices along the way. For us, this has meant leveraging our internally facing \#iteachmsu Commons, the websites of educator development units, and Twitter. Our choice of platform(s) depends on the audience skills and needs, purpose of the ELC event, and/or centralized marketing priorities and strategies.

- A common community identifier, such as a hashtag. Since the conversations of an ELC will happen across multiple digital platforms and at both synchronous and asynchronous moments, it's also important to have a common community identifier, such as a hashtag, to easily gather and curate what is emerging from the conversations. For us, the hashtag has allowed for easily aggregating the results of social media conversations and then sharing them back with some of the more internally facing communities at our institution. We use these hashtags across both Twitter and our internally curated \#iteachmsu Commons site. And we select these hashtags based on topic 
focus, community recognition, and current events on campus and beyond.

- User-generated content. One of the core strengths of an ELC is that it is user driven and grassroots. This allows the community to truly leverage the innovations happening across campus (especially large ones such as ours). Instead of going through traditional editorial processes and/or communications strategies and calendars, create ways for educators across your ELC to post content and ideas as they emerge. For us, this oftentimes happens through EdChats and usergenerated posts on our \#iteachmsu Commons site.

- Facilitation of connections between users, ideas, or resources. Since an ELC is focused on leveraging the best aspects of both centralized support and decentralized innovations, it's important for central facilitators to deliberately cultivate connections emerging across the ELC. We've found this especially important as the ELC is developing and before further campus-wide champions have emerged. For us, this has meant regularly connecting users, ideas, and/or resources through centrally supported events, on the main web pages of educator development unit websites, and through social media. Oftentimes this has meant combining them all, for example, by hosting a live event, facilitating a conversation around that live event on Twitter, and then posting resources from both on the \#iteachmsu Commons shortly afterward.

- Balancing central resourcing and facilitation and decentral innovations toward centering teaching and learning. With the main focus of an ELC being centering teaching and learning, it's essential to keep an eye to how teaching and learning practice and value are being built out across campus. This means providing essential central resourcing (e.g., funding, valuation through tenure and promotion, toolkits, competency frameworks) but all with the intention of seeding the growth of sustainable educator development across campus. For us, this has meant providing central guidance on teaching competency areas, sponsoring workshops that educators in the network have wanted to facilitate, building a toolkit-based on 
teaching competency areas-to help deans and chairs integrate our ELC into tenure and promotion processes, and even participating in a campus-wide educator awards program facilitated through the Provost's Office.

- Programming (whether face-to-face or digital) that is inclusive of multiple educator identities and focuses on both central priorities and decentralized innovations. A key strength of our ELC is that it is inclusive of the variety of educator identities across our campus. The multiple individuals who help advance the teaching and learning mission of our university are included (faculty, graduate teaching assistants, academic staff, learning experience designers, administrators, etc.). This allows us to better center the value of teaching and learning across campus as we are able to leverage the work of multiple champions in addition to faculty. For us, this has meant emphasizing the teaching and learning competencies at the core of our programming, explicitly focusing audiences on the goal of centering these competencies across campus, and further emphasizing how these competencies are shared across educator roles. We also deliberately make sure that formal leadership and/or facilitation of programming is shared across this diverse group of educators as well as providing integrated face-to-face and digital options (e.g., a faceto-face workshop combined with a Twitter chat). These practices allow us to further cultivate this diverse community and to benefit from the rich diversity of voices, experiences, and innovations that emerge.

Ownership of facilitation for the ELC is important but does not necessarily fall under the purview of already established institutional roles. Communication around the availability and mission of a new ELC will also be vital, as participation is voluntary and fluctuating and content is heavily user generated. Administrators should consider the best integration of existing institutional structures that potentially support educator professional development. These communities inherently assume voluntary participation and some level of confidence using 
SNS affordances. And there will still be institution-specific challenges for designing and implementing an ELC model. Lastly, scholarship and sharing about an ELC are important.

While our stories and steps vary, our author group has become powerfully centered across our work as educators through \#iteachmsu. We have continued to sustain the work and one another in ways that have led to powerful collaborations across our institution. We did this without a traditional teaching center or single central space that was solely resourced to support the teaching and learning mission of the university. Instead, we sought and seek ways to leverage decentralized innovations and centralized resources from multiple vantage points. And while there are many steps and stories still ahead, we believe our connections across our institution and the larger work of \#iteachmsu to be initial proof and impetus for continuing forward.

\section{Reflections and Next Steps}

We see \#iteachmsu as a true rallying cry. We, along with a diverse community of educators, educate others across our various roles on this campus. Through the use of this hashtag and the digital and faceto-face spaces connected to it, we've become deeply connected through centering our work as educators across campus. By creating a space where diverse educators are celebrated and can come together in collaboration and collective problem-solving, we hope to further build an institution that centers teaching and learning at the core of its efforts. With \#iteachmsu, over time, we hope faculty and staff work at our university because their educator efforts will be valued and supported. We hope future students come to our university because they are excited to learn with and from educators across identities who are centered in their collective value of teaching and learning.

With the COVID-19 pandemic as a catalyst, \#iteachmsu Commons is the home to many of the resources and efforts supporting educator development. With a growing user base, we are looking forward to 
the learning opportunities presented by an increase in platform data. More research is certainly needed to utilize this data and determine best practices, effective assessment tools, and alternative designs for our ELC. To do so, future research on building our ELC will be centered in the following questions:

1. How do educators respond to the \#iteachmsu Commons ELC (whether face-to-face or digital)?

2. How do these educator responses potentially influence college/ department/institution teaching and learning cultures?

3. What further educator needs emerge as educators and their colleges/departments/institution respond to our work in the \#iteachmsu Commons ELC?

As we begin to answer these questions, we hope to witness building of further connections such as those we've so valued across our multiple educator identities.

\#iteachmsu represents possibility. It represents the possible future when educators feel supported in their own professional development. It represents the co-construction of a value system educators desire and the possible future when that system is valued within and by the institution. It represents the possibility of a much broader and more expansively shared commitment to changing existing structures, rewriting existing narratives, and reframing our dedication to education and student success. It represents the possibility of a network that recognizes and celebrates all educator identities and not just those that exist within a traditional classroom. Beyond that, it centers growth, agency, communication, and collaboration by and for an educator learning community.

\section{Biographies}

Erik Skogsberg, PhD, is the VP of Learning Experience for Voltage Control (www.voltagecontrol.com), a facilitation agency that helps 
teams work better together with custom-designed meetings and workshops, both in-person and virtual. Prior to working at Voltage Control, he was Associate Director and Head of Design at the MSU Hub for Innovation in Learning and Technology. His consulting, research, and teaching focus on designing learning experiences, teaching and facilitation, innovation, design, and organizational change.

Makena Neal, PhD, is an Academic Specialist at the MSU Hub for Innovation in Learning and Technology and recently completed her PhD in Higher, Adult, and Lifelong Education. Her professional and scholarly goals are to help amplify, elevate, and celebrate the innovative practices of educators in the MSU community. Makena's work focuses on efforts and initiatives that recenter teaching and learning by advancing MSU's culture toward recognition and support for all educators.

Melissa McDaniels, PhD, is Associate Executive Director and Associate Scientist at the Center for the Improvement of Mentored Experiences in Research (CIMER, www.cimerproject.org) at the University of Wisconsin-Madison. From 2013 to 2020, in her role as member of the MSU Graduate School leadership team, Dr. McDaniels worked to support graduate students and postdocs as they developed their capacities as postsecondary instructors and mentors. From 2008 to 2012, McDaniels served as Director of MSU's NSF ADVANCE Grant.

Madeline Shellgren is the Director of Online Engagement for the Online Learning Consortium (OLC), where she serves as the lead innovator, designer, and project manager of the OLC's portfolio of online engagement opportunities. Prior to this position, she supported a variety of educator professional development initiatives at MSU. Maddie is currently working toward the completion of her doctoral degree in Writing, Rhetoric, and American Cultures at MSU.

Patricia Stewart, PhD, is Director of Instructional Development for MSU's Academic Advancement Network. Patti has worked in faculty 
development and instructional technology at MSU since 2003. In her current role, she coordinates teaching and learning programs and learning communities, facilitates teaching and learning cohort programs, and conducts instructional development consultations and conversations. Her areas of specialization include educational technology and online learning, faculty development, new media design and implementation, and online course/program design.

\section{References}

Alexander, B. (2006). Web 2.0: A new wave of innovation for teaching and learning? EDUCAUSE Review, 41(2), 32-44.

American Council on Education \& POD Network. (2018). A center for teaching and learning matrix. https://podnetwork.org/content/uploads/ACE-PODTeaching-Center-Matrix-2018.pdf

Austin, A., \& McDaniels, M. (2006). Preparing the professoriate of the future: Graduate student socialization for faculty roles. In J. C. Smart (Ed.), Higher education: Handbook of theory and research (Vol. 21, pp. 397-456). Springer.

Baker-Doyle, K. J. (2017). Transformative teachers: Teacher leadership and learning in a connected world. Harvard Education Press.

Banasik, M. D., \& Dean, J. L. (2016). Non-tenure track faculty and learning communities: Bridging the divide to enhance teaching quality. Innovative Higher Education, 41(4), 333-342.

Bauer, W. I. (2010). Your personal learning network: Professional development on demand. Music Educators Journal, 97(2), 37-42. https://doi. org/10.1177/0027432110386383

Beach, A. L., Sorcinelli, M. D., Austin, A. E., \& Rivard, J. K. (2016). Faculty development in the age of evidence: Current practices, future imperatives. Stylus Publishing.

Boyer, E. L. (1990). Scholarship reconsidered: Priorities of the professoriate. Carnegie Foundation for the Advancement of Teaching.

Boyle, P., \& Boice, B. (1998). Systematic mentoring for new faculty teachers and graduate teaching assistants. Innovative Higher Education, 22(3), 157-179.

Brew, A. (2006). Research and teaching: Beyond the divide. Palgrave Macmillan.

Cox, M. D. (1995). The development of new and junior faculty. In A. W. Wright et al. (Eds.), Teaching improvement practices: Successful strategies for 
higher education (pp. 283-310). Professional and Organizational Development Network in Higher Education.

Cox, M. D. (1999). Peer consultation and faculty learning communities. New Directions for Teaching \& Learning, 1999(79), 39-49.

Cox, M. D. (2004). Introduction to faculty learning communities. In M. D. Cox \& L. Richlin (Eds.), Building faculty learning communities (pp. 5-23). Jossey-Bass.

Cox, M. D. (2013). The impact of communities of practice in support of earlycareer academics. International Journal for Academic Development, 18(1), 18-30.

Davis, M., \& Holt, M. E. (1998). havingproblems@cm.com: New ways to miss the point. Innovative Higher Education, 22(4), 311-327.

Eddy, P. L., \& Garza Mitchell, R. L. (2012). Faculty as learners: Developing thinking communities. Innovative Higher Education, 37(4), 283-296.

Froyd, J. E., Henderson, C., Cole, R. S., Friedrichsen, D., Khatri, R., \& Stanford, C. (2017). From dissemination to propagation: A new paradigm for education developers. Change: The Magazine of Higher Learning, 49(4), 35-42. https://doi.org/10.1080/00091383.2017.1357098

George, D. R., \& Dellasega, C. (2011). Use of social media in graduate-level medical humanities education: Two pilot studies from Penn State College of Medicine. Medical Teacher, 33(8), e429-e434.

Hanraets, I., Hulsebosch, J., \& de Laat, M. (2011). Experiences of pioneers facilitating teacher networks for professional development. Educational Media International, 48(2), 85-99.

Hollins, E. R. (2011). Teacher preparation for quality teaching. Journal of Teacher Education, 62(4), 395-407.

Hubbal, H., \& Albon, S. (2007). Faculty learning communities: Enhancing the scholarship of teaching, learning, and curriculum practice. Journal on Excellence in College Teaching, 18(2), 119-141.

Huber, M. T., \& Hutchings, P. (2005). The advancement of learning: Building the teaching commons. Jossey-Bass.

Joshi, M., \& Chugh, R. (2009). New paradigms in the teaching and learning of accounting: Use of educational blogs for reflective thinking. International Journal of Education and Development Using ICT, 5(3).

Kelley, B., Cruz, L., \& Fire, N. (2017). Moving toward the center: The integration of educational development in an era of historic change in higher education. To Improve the Academy, 36(1), 1-8. https://doi.org/10.1002/tia2.20052

Lampert, M. (2010). Learning teaching in, from, and for practice: What do we mean? Journal of Teacher Education, 61(1-2), 21-34.

Lave, J. (1991). Situating learning in communities of practice. In L. B. Resnick, J. M. Levine, S. D. Teasley (Eds.), Perspectives on socially shared cognition (pp. 63-82). American Psychological Association. 
Li-Ping Tang, T., \& Chamberlain, M. (1997). Attitudes toward research and teaching: Differences between administrators and faculty members. The Journal of Higher Education, 68(2), 212-227.

Locke, W. (2012). The dislocation of teaching and research and the reconfiguring of academic work. London Review of Education, 10(3), 261-274.

Manca, S., \& Ranieri, M. (2013). Is it a tool suitable for learning? A critical review of the literature on Facebook as a technology-enhanced learning environment. Journal of Computer Assisted Learning, 29(6), 487-504.

McLoughlin, C., \& Lee, M. J. W. (2008). Future learning landscapes: Transforming pedagogy through social software. Innovate: Journal of Online Education, $4(5)$.

Oleson, A., \& Hora, M. T. (2014). Teaching the way they were taught? Revisiting the sources of teaching knowledge and the role of prior experience in shaping faculty teaching practices. Higher Education, 68(1), 29-45.

Powell, D. A., Jacob, C. J., \& Chapman, B. J. (2012). Using blogs and new media in academic practice: Potential roles in research, teaching, learning, and extension. Innovative Higher Education, 37, 271-282.

Sherer, P. D., Shea, T. P., \& Kristensen, E. (2003). Online communities of practice: A catalyst for faculty development. Innovative Higher Education, 27(3), 183-194.

Shulman, G. M., Cox, M. D., \& Richlin, L. (2004). Institutional considerations in developing a faculty learning community program. New Directions for Teaching and Learning, 2004(97), 41-49.

Shulman, L. S. (1986). Those who understand: Knowledge growth in teaching. Educational Researcher, 15(2), 4-14.

Shulman, L. (1987). Knowledge and teaching: Foundations of the new reform. Harvard Educational Review, 57(1), 1-23. https://doi.org/10.17763/ haer.57.1.j463w79r56455411

Trust, T. (2012). Professional learning networks designed for teacher learning. Journal of Digital Learning in Teacher Education, 28(4), 133-138. https:// doi.org/10.1080/21532974.2012.10784693

Warlick, D. (2009). Grow your personal learning network: New technologies can keep you connected and help you manage information overload. Learning \& Leading With Technology, 36(6), 12-16.

Wenger, E. (2000). Communities of practice and social learning systems. Organization, 7(2), 225-246.

Wright, M. (2016). Evidence-based principles for online faculty development. https://er.educause.edu/articles/2016/11/evidence-based-principles-for-onlinefaculty-development

Wright, M. C., Lohe, D. R., \& Little, D. (2018). The role of a center for teaching and learning in a de-centered educational world. Change: The Magazine 
of Higher Learning, 50(6), 38-44. https://doi.org/10.1080/00091383.2018. 1540826

Yang, G. (2016). Narrative agency in hashtag activism: The case of \#BlackLivesMatter. Media and Communication, 4(4), 13-17. https://doi.org/10.17645/ mac.v4i4.692 